\title{
A politico-economic model of public expenditure and income taxation
}

\author{
Laura Mayoral $^{1}$. Joan Esteban ${ }^{1}$
}

Received: 26 February 2019 / Accepted: 3 July 2019 / Published online: 17 July 2019

(c) The Author(s) 2019

\begin{abstract}
This paper contributes to the literature on majority voting over fiscal policies. We depart from the standard model in two dimensions. First, besides redistributing income, the government uses the net tax revenue to finance the provision of goods and services that become in-kind transfers to the citizens. By deciding on the composition of this expenditure (education, health, law-and-order, etc.), the government chooses the allocation of the benefits to the different income segments. This choice is a fundamental ingredient of fiscal policy. Second, we tackle the problem of choosing the income tax function and the composition of public expenditure by assuming that the political process selects one of these issues as the salient one. Political controversy and vote focus on this issue exclusively. The other dimension is determined in a way so as to minimize objections (obtain consensus) among the voters. We analyze the case where the salient policy is the composition of public expenditure. We show that for each voted expenditure policy, there is a unique income tax function that attains consensus. The political process we model yields that the progressiveness of the income tax schedule depends on income inequality interacted with the elasticity of substitution of the goods provided in the market and those publicly provided. This relationship is confirmed in our empirical test.
\end{abstract}

Keywords Government policy · Income taxation · Inequality · Public expenditure · Size of government

JEL Classification H23 · H50

Electronic supplementary material The online version of this article (https://doi.org/10.1007/s13209019-0198-4) contains supplementary material, which is available to authorized users.

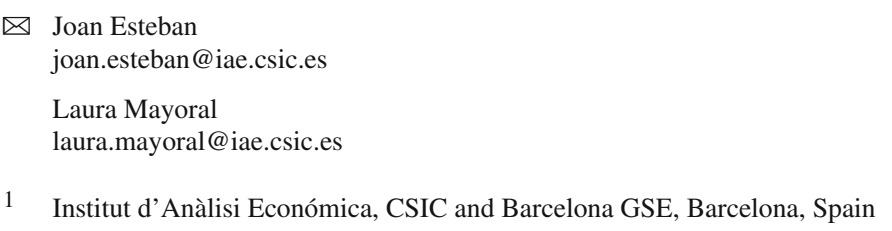




\section{Introduction}

Political economy models of fiscal policy have typically treated separately the choice of income taxation and the choice of public spending. Models of income taxation have focused on voting over purely redistributive linear tax schedules, where individuals care about labor effort and disposable income only. This approach ignores the complementary role of taxation as a source of revenue to finance the government's supply of goods and services, the in-kind transfers, such as education or health. The classic result in this literature is that the tax rate that obtains majoritarian support is the one preferred by the voter with the median income and that the marginal tax rate is increasing in the gap between the mean and the median income. ${ }^{1}$ Such neat and intuitive result has not obtained support from the data. ${ }^{2}$

In this paper, we explore the possibility that these poor empirical results could be improved by enriching the model by jointly considering the choice of the income tax schedule and the composition of public expenditure. Our point is that individuals care about (private) consumption but also about in-kind benefits from goods and services supplied by the government. Hence, there is a trade-off in the evaluation of higher taxation: It reduces disposable income, but it increases the amount of the goods supplied by the government. It follows that the choice of these fiscal policies (the income tax schedule and the composition of public expenditure) should be jointly modeled.

In this paper, we consider jointly the determination of the income tax schedule and the composition of public expenditure. Our starting point is the fact that public debate typically concentrates on a reduced set of salient issues. Political scientists have thoroughly studied the relative importance of expenditure policy and income taxation in the political debate. As it appears, partisan competition turns out to be strong on expenditure policy and mild on income taxation. ${ }^{3}$ This view is patent, for instance, in the codification of party manifestos in all democratic countries since 1945 by Budge et al. (2001, 2006). Income taxation or income redistribution has such a modest presence in the manifestos that neither deserve an entry as a relevant topic. In contrast, public good expenditure on issues such as environment, culture, social services, social security, health, or education represents nearly 20 percent of total entries. Bruninger (2005) and Tsebelis and Chang (2004) find evidence of a significant effect of the composition of governments on the type of public spending.

Inspired by this, we choose the salient issue to be the composition of public spending.

The political economy model that we envisage is based on these observations and redefines the political process for the choice of fiscal policy variables as follows: (i) The salient issue over which individuals vote-and political parties base their manifestos-is the composition of public spending, more specifically, the extent to which the kind of goods and services provided benefits the poor or the rich; and (ii) given the voted expenditure policy, the political actors look for a distribution of

\footnotetext{
1 Romer (1975), Roberts (1977), and Meltzer and Richard (1981).

2 Borck (2007) and Scervini (2012) in their surveys on inequality and income tax progressivity conclude that there is no solid evidence in support of the critical role of the median income voter.

3 Chris Wales, advisor to the former UK prime minister Gordon Brown, stated: In the Parliament "there is almost no examination of the design of the tax system as a whole," The Telegraph (18/10/2007).
} 
the tax burden, an income tax schedule, that minimizes controversy and does not open additional fronts of partisan confrontation. Our results show that for any chosen expenditure policy, there exists a unique consensual tax function [to be made precise as follows], with the corresponding net tax revenue and the budget balancing size of government. Consequently, voting over the salient issue and designing the rest so as to be consensual deliver the simultaneous determination of expenditure and taxation policies.

With regard to public expenditure, the government uses the net tax revenue to finance the public supply of goods and services, which constitute the provided in-kind benefits. As in Arrow (1971), we assume that the government can target the individual beneficiaries of its expenditure by choosing the weight given to types of expenditure that mostly benefit each specific segment of the income ladder. We consider two different expenditure principles. One is equal treatment, providing a uniform benefit across the population. The other is incentive-motivated and provides benefits in accordance with the individual fiscal effort. We parametrize the expenditure policies by the weight given to the egalitarian principle relative to the incentives motive. The value of this parameter is chosen by majority voting.

The impact of the public provision of goods on individual well-being critically depends on whether those goods can be substituted by goods that are privately provided through the market. This will also have a critical impact on attitudes toward taxation. Consider, for instance, the case when security was the monopoly of the public police force, with no close substitute in the private market, rich individuals with a high demand for security had to accept a well-funded government because there was no other way of obtaining it. As soon as private security can be purchased in the market, the taxpayers might find the state more dispensable and hence are less willing to pay taxes. The joint determination of the income tax schedule and the composition of the public expenditure, with individuals caring about market and publicly provided goods, sheds new light on the relationship between the progressiveness of income taxation and income inequality. Our model predicts this relationship to be mediated by the elasticity of substitution between market and publicly provided goods. ${ }^{4}$

More specifically, our model delivers two main implications: (1) There is a positive relationship between the marginal tax rate and inequality when the elasticity of substitution private/public is low, and a negative relationship when this elasticity is high; and (2) the size of government is negatively related to inequality, and the marginal effect of inequality on the size of government is larger (in absolute value) if the value of the elasticity of substitution is lower.

We test these predictions by considering a panel of (at most) 131 countries over the period 1981-2008, and our empirical results are in line with the model predictions.

What is the net value added of our shifting of partisan competition from income taxation to public expenditure? This shift yields three interesting novel insights: (i) It brings into stage the interdependence between taxation and public expenditure in in-kind transfers; (ii) it unveils the impact on fiscal policy from public decisions modifying the substitutability between publicly supplied goods and market goods [via

\footnotetext{
4 We take this substitutability parameter as given and leave for future research the rationale of the privatization of public services as a way of changing such substitutability by shifting goods from public to private provision.
} 
privatizations, for instance], and (iii) it explains why inequality has a non-monotonic relationship with income tax progressivity, through its interaction with the substitutability of public versus privately supplied goods and services.

The paper is organized as follows. In Sect. 2, we present the model. In Sect. 3, we obtain the consensus income tax schedule and government size, associated with each chosen expenditure policy and show that the majoritarian expenditure policy will be the one preferred by the individual with the median income. All the proofs are in "Appendix A." We specifically examine the case with CES preferences. Section 4 empirically tests the two main implications of our model, and Sect. 5 concludes. Additional results related to the empirical analysis and not included in the main text can be found in Online Appendix ("Appendix B").

\section{The model}

We assume a unit mass continuum of individuals. Individual income, denoted by $y$, is exogenous and distributed over the population with cdf $F$ and support $[a, \infty), a>0$. We are, thus, implicitly assuming a rigid labor supply. ${ }^{5}$ We shall denote the average per-capita income by $\bar{y}$.

Individual preferences are defined over private consumption $x$ and over a publicly supplied good $g$. The publicly supplied good can be public or private in nature or a mixture of the two. The essential distinguishing feature here is that $x$ is purchased in the market while $g$ is fixed by the government.

Individual preferences are represented by $u(x, g)$. On individual preferences, we make the following standard assumption:

Assumption $1 u_{x}>0, u_{g}>0, u_{x x}<0, u_{g g}<0$ and $u_{x g}>0$. For $g>0$, $\lim _{x \rightarrow 0} u_{x}=\infty$ and $\lim _{x \rightarrow \infty} u_{x}=0$, and for $x>0, \lim _{g \rightarrow 0} u_{g}=\infty$ and $\lim _{g \rightarrow \infty} u_{g}=0$.

Let $t(y), t(y) \leq y$, denote the tax paid [transfer received if negative] by an individual with income $y$. The entire disposable income is consumed and hence

$$
x(y)=y-t(y) .
$$

We depart from the standard literature on income taxation in that we let the tax schedule to produce a positive net revenue. This revenue is used to finance the public supply of $g$.

We denote by $\bar{t}$ the per-capita net tax revenue, i.e.,

$$
\bar{t}=\int t(y) \mathrm{d} F(y) .
$$

We are interested in the type of goods and services provided by the government. The structure of public expenditure is important because, by choosing the weight allocated

\footnotetext{
5 We show at the end of Sect. 3.1 that our results go through with endogenously chosen labor supply.
} 
to the different types of goods and services, it establishes the distribution of the benefits produced. Transferring resources from primary education or from health to foreign representation or law-and-order, for instance, tilts the benefits of public expenditure toward rewarding the tax effort of the high taxpayers. ${ }^{6}$

Although we will treat public expenditure as an aggregate, we want our model to capture the distributive bias implicit in expenditure policy. A stark way of representing the distributional impact of public expenditure is to consider the chosen policy as a compromise between two principles that seem to inspire the debate. On the one hand, we have the principle of universal and equal treatment of all the citizens. This principle recommends a structure of public expenditure that produces an equal benefit across the board. Hence, the extreme form of this principle is to choose the public expenditure so that $g(y)=\bar{g}$, the mean expenditure. On the other hand, we have the notion of making the benefits of governmental action to be proportionate to the fiscal effort exerted by the different tax payers. The extreme reading of this second principle would advocate for public spending fully responsive to the principle of rewarding the taxpayer effort and thus return as benefits to each taxpayer the exact amount of taxes paid, $g(y)=t(y)$. We shall consider public expenditure as a weighted mixture of these two extreme principles. The stronger the role of the egalitarian principle, the more beneficial to the poor the expenditure policy will be.

We consider the family of expenditure policies that are a mixture of these two extreme positions. ${ }^{7}$ Therefore, we define an expenditure policy by $\gamma$ the weight given to the egalitarian policy. The benefit from public expenditure resulting from $\gamma$ is

$$
g(y, \gamma)=\gamma \bar{g}+(1-\gamma) t(y)=\bar{g}+(1-\gamma)(t(y)-\bar{g})=\bar{g}+(1-\gamma)(t(y)-\bar{t})
$$

For $\gamma \in[0,1)$, the expenditure policy will benefit the taxpayer giving to her in-kind benefits above the average $\bar{g}$. When $\gamma>1$, the expenditure policy benefits the poor giving to the ones contributing below average extra in-kind benefits. ${ }^{8}$

A fiscal policy consists of an income tax/transfer and an expenditure policy: $[t(\cdot), \bar{g}, \gamma]$. Notice, however, that our parametrization of the bias of public expenditure makes that the government's budget is always balanced because

$$
\bar{g} \equiv \int g(y) \mathrm{d} F(y)=\bar{t} .
$$

\footnotetext{
6 For instance, the judiciary system deals with a disproportionate share of cases filed by private businesses or by the rich. The stockholders also benefit from the services provided by the foreign service to help the national firms to export or to invest abroad.

7 This class of policies is a specification of the targeted expenditure policies considered in Arrow (1971).

${ }^{8}$ Let us write $\gamma(y)=\frac{g(y)-t(y)}{\bar{g}-t(y)}$. Using data from the UK Office of National Statistics (2013) for 2012 and 2013, we have the estimates for each income quintile of $t(y)$, the income tax paid, and $g(y)$, the in-kind transfer received. Therefore, we can obtain the implicit $\gamma(y)$ for each quintile with per-capita income $y$ : [fiscal year 2011 to 2012]: $\gamma_{1}=1.16, \gamma_{2}=1.13, \gamma_{3}=1.30, \gamma_{4}=1.24, \gamma_{5}=1.14$. [fiscal year 2012 to 2013]: $\gamma_{1}=1.16, \gamma_{2}=1.19, \gamma_{3}=1.12, \gamma_{4}=1.14, \gamma_{5}=1.10$. Therefore, the in-kind benefits of the UK fiscal system can be reasonably approximated by our rule in (3) with a pro-poor parameter of about $\gamma=1.14$ for all quintiles.
} 
The larger the value of $\gamma$, the more redistributive the expenditure policy is. It is unquestionable that reducing expenditure policy to one parameter does not pay justice to the subtleties of public spending. But this is the price-we hope that worth the while-we have to pay to make the voting on public expenditure tractable. Yet, in spite of its extreme simplicity, we think that synthesizing public expenditure as a compromise between these two extreme policies does capture a substantial part of the essence of the choices at stake, as we have seen for the case of the UK.

The utility of an individual with income $y$ from the fiscal policy $[t(\cdot), \bar{g}, \gamma]$ is

$$
u(y-t(y), \gamma \bar{g}+(1-\gamma) t(y))
$$

We denote by $\vartheta$ the size of government: $\vartheta=\frac{\bar{g}}{\bar{y}}$.

We now proceed to the discussion of the choice of fiscal policy.

\section{The political economy of fiscal policy}

We have already reported in the Introduction the evidence on partisan competition appearing to be strong on expenditure policy and very mild on income taxation. Inspired by these observations, we redefine the political process for the choice of fiscal policy as follows: (i) The salient issue over which individuals vote-and political parties base their manifestos-is $\gamma$; and (ii) given the voted $\gamma$, the political actors_-political parties, civil servants, parliamentary committees, lobbies, or expert advisors-look for an allocation of the tax burden $t(y)$ that minimizes controversy. The size of government $\vartheta$ is determined by the chosen income tax function.

We solve the problem backward. Section 3.1 shows that for each $\gamma$, there is a unique consensual income tax schedule $t(\cdot)$ and hence $\vartheta$, min Sect. 3.2. Section 3.3 deals with choosing by majority voting over the size of $\gamma$. We end our analysis of the choice of fiscal policy in Sect. 3.4 by obtaining close-form solution for CES preferences.

\subsection{Consensual taxation}

A tax function is any strictly increasing function from $\Re$ to $\Re$. We denote by $\Theta$ the set of all such functions. Notice that this set contains all the strictly increasing functions with any net tax revenue. A tax function $t(\cdot) \in \Theta$ is acceptable to an individual with income $y$ if she does not wish to vary its progressivity and it is consensual if it is unanimously acceptable. In order to operationalize the notion of "variation of the progressivity" of $t(\cdot)$, we focus on affine transformations $\tilde{t}(\cdot)$ that leave the net revenue constant, that is:

$$
\tilde{t}(y)=\bar{t}+\beta[t(y)-\bar{t}] .
$$

Consider any arbitrary $t(\cdot) \in \Theta$ and any given $\gamma$. The valuation of a change in progressiveness by $\beta$ by an individual with income $y$ will be

$$
u(y-[\bar{t}+\beta(t(y)-\bar{t})], \gamma \bar{t}+[1-\gamma][\bar{t}+\beta(t(y)-\bar{t})]) .
$$


Given a tax function $t(\cdot)$ we denote by $\beta(t(\cdot), y)$ the change that would be preferred by an individual with income $y$. Since the utility is strictly concave in $\beta$, the most preferred change in progressiveness can be obtained from the first-order condition.

Definition 1 (i) A tax function $t(\cdot) \in \Theta$ is individually acceptable to a person with income $y$ if $\beta(t(\cdot), y)=1$. The set of acceptable tax functions to an individual with income $y$ is denoted by $\Im(y)$.

(ii) A tax function $t(\cdot) \in \Theta$ is consensual if it is unanimously acceptable, that is, if $t(\cdot) \in \bigcap_{y} \Im(y) \equiv \Im$.

For a tax schedule be acceptable by an individual with income $y$, it has to be that utility is maximal for $\beta=1$ over all the affine transforms defined in (6). Differentiating the utility with respect to $\beta$ in (7), equating it to zero, and evaluating at $\beta=1$ we obtain

$$
\frac{u_{x}(y-t(y), \gamma \bar{t}+(1-\gamma) t(y))}{u_{g}(y-t(y), \gamma \bar{t}+(1-\gamma) t(y))}=1-\gamma .
$$

Because of Assumption 1, the left-hand side of (8) is strictly increasing in $t(y)$, it goes to infinity as $t(y) \rightarrow y$ and to zero as $t(y) \rightarrow-\frac{\gamma}{1-\gamma} \bar{t}$. Hence, for each $\bar{t}$ and $y$ there exists a unique $t(y)$ satisfying (8). We can thus write $t(y)=\psi(y, \bar{t}, \gamma)$. It can be readily verified that $\psi$ is continuous and strictly increasing in $y$ and continuous and strictly decreasing in $\bar{t}$.

If $t(y)$ is universally acceptable, this condition has to be satisfied by all incomes and the budget has to balance. The arbitrary parameter $\bar{t}$ is fixed by imposing budget balance, that is

$$
\bar{t}=\int \psi(y, \bar{t}, \gamma) \mathrm{d} F(y) .
$$

In order to show that a unique such $\bar{t}$ exists, we start by noting that by Assumption 1 at $\bar{t}=0$ we have that $\psi(y, 0, \gamma)>0$ for all $y$, and we have already shown that $\psi$ is strictly decreasing in $\bar{t}$. Therefore, $\int \psi(y, \bar{t}, \gamma) \mathrm{d} F(y)$ is strictly decreasing in $\bar{t}$ and $\int \psi(y, 0, \gamma) \mathrm{d} F(y)>0$. It follows that there always exists a unique $\bar{t}$ that satisfies the budget constraint.

Summing up, for every distribution of income $F$ and every $\gamma$ there is a unique tax function $t(\cdot) \in \Theta$ that is budget balancing and consensual.

Formally,

Proposition 2 Let individual preferences satisfy Assumption 1. For any income distribution $F(\cdot)$ and any given $\gamma>0$, the set $\mathfrak{\Im}$ is non-empty and contains one single element only.

We now show that the obtained consensual tax function displays the standard property of the marginal tax be between zero and unity in all the support.

Proposition 3 The marginal tax rate of the consensus tax function satisfies $0 \leq t^{\prime}(\cdot)$ $\leq 1$.

Before proceeding with the voting over the bias in public expenditure, we wish to make four points on the previous result. 
1. The first point refers to the restriction on the tax function: The set $\Im(y)$ contains tax functions yielding very different aggregate tax revenues. The restriction that a tax function is consensual and, hence, acceptable to all selects not only the consensual steepness of the tax function, but also its net revenue. The aggregate tax revenue — and hence the size of government $\vartheta$-is determined together with the shape of the tax function.

2. Our second point concerns the importance of the assumption that incomes are exogenous. The existence of a consensual tax function remains intact with an elastic labor supply. To see this observe that, written in compact form, the preferred $\beta$ implies that $\frac{\mathrm{d} u}{\mathrm{~d} \beta}=\frac{\mathrm{d} u}{\mathrm{~d} t(y)}[t(y)-\bar{t}]=0$. We then examine the implications of this condition being satisfied for $\beta=1$ for all incomes. With individual choice of labor supply, income would be $y=w \ell$, where $\ell$ is labor supply and $w$ the wage rate. Preferences will now (negatively) depend on a third commodity: labor supply $\ell$. The utility maximizing choice of $\ell$ would entail that the total marginal effect on utility be zero, that is, that $\frac{\mathrm{d} u}{\mathrm{~d} \ell}=0$. Now, the effect on the utility of a change in $\beta$ depends on the total direct effect on utility of changing the tax, together with the induced change in utility via the change in labor supply. This total change has to equal zero. If we compute the total change, we now have $\frac{\mathrm{d} u}{\mathrm{~d} t(y)}[t(y)-\bar{t}]+\frac{\mathrm{d} u}{\mathrm{~d} \ell} \frac{\mathrm{d} \ell}{\mathrm{d} t(y)}[t(y)-\bar{t}]$ that, by an envelope argument, reduces to the previous expression $\frac{\mathrm{d} u}{\mathrm{~d} t(y)}[t(y)-\bar{t}]=0$. We have opted for a rigid labor supply for the sake of the clarity of our arguments.

3. Our third point wishes to stress that consensual taxes also satisfy the property of being welfare maximizing relative to the other tax schedules with the same net tax revenue. Notice that the requirement that for the chosen $t(\cdot)$ no one can improve upon by local affine transformations is in fact a standard variational condition to characterize a function that maximizes the integral of individual utilities. ${ }^{9}$

4 Our last point is that, as already mentioned above, one can equivalently solve the problem of characterizing the expenditure policy and the tax function that are consensual for any given size of government $\vartheta$ - and hence for given $\bar{t}$. Define $\hat{t}(y)$ as the optimal amount of income that an individual with income $y$ would like to turn into goods and services publicly provided if allowed to. That is, $\hat{t}(y)$ satisfies $u(y-\hat{t}(y), \hat{t}(y)) \geq u(y-t(y), t(y))$. Let $\hat{t}=\int \hat{t}(y) \mathrm{d} F(y)$. Let us now consider the marginal utility of publicly supplied goods $u_{g}$ for an individual with income

9 To see this result, let $t^{*}(\cdot)$ be the consensus tax function and $t(\cdot)$ any alternative tax function with the same tax revenue and write

$$
W\left(t^{*}(\cdot)\right)-W(t(\cdot))=\int\left[u\left(y-t^{*}(y), \gamma t^{*}(y)+(1-\gamma) \bar{t}^{*}\right)-u\left(y-t(y), \gamma t(y)+(1-\gamma) \bar{t}^{*}\right)\right] \mathrm{d} F(y) .
$$

Since $u(\cdot, \cdot)$ is concave in the tax function, and using the FOC (8), we can write

$$
\begin{aligned}
& W\left(t^{*}(\cdot)\right)-W(t(\cdot)) \\
& \quad \geq \int\left[t^{*}(y)-t(y)\right]\left[-u_{x}\left(y-t^{*}(y), \gamma t^{*}(y)+(1-\gamma) \bar{t}^{*}\right)+\gamma u_{g}\left(y-t^{*}(y), \gamma t^{*}(y)\right.\right. \\
& \left.\left.\quad+(1-\gamma) \bar{t}^{*}\right)\right] \mathrm{d} F(y)=0 .
\end{aligned}
$$


$y$ and paying taxes $t(y)$. A marginal increase in the tax paid will decrease private consumption and increase the consumption of the publicly provided goods. The joint effect of these changes clearly is a decrease in $u_{g}$. Our assumption is that the elasticity of this change in the marginal utility of the publicly provided goods is less than unity. Formally, our assumption is as follows.

Assumption 2 We assume that for all incomes and all $\gamma \in(0,1)$

$$
-\frac{t(y)}{u_{g}} \frac{\partial u_{g}}{\partial t(y)} \leq 1 .
$$

With this additional assumption, one can easily prove that for every income distribution $F(\cdot)$ and for any size of government $\vartheta \in\left(0, \frac{\tilde{t}}{\mu}\right)$ there exists a unique $\gamma>0$ and a unique consensual and budget balancing tax function $t(\cdot) .^{10}$

Summing up, we have presented a different modeling of the political economy of the choice of fiscal policy in which the political debate essentially falls on the type of goods and services to be supplied by the government. By choosing the composition of the public spending, the government can target the benefits to the different income levels. This is the politically salient issue. The income tax function is designed to minimize rejection and hence not to become a competing salient issue in the political debate. The notion of consensual taxation has enough bite to single out a unique tax function that we completely characterize. Furthermore, the resulting tax function has the property that it is welfare maximizing.

\subsection{Expenditure policy and size of government}

We have seen that for each expenditure policy $\gamma$, there is a unique consensual tax schedule with its associated net tax revenue. By budget balance, this tax revenue determines the size of government $\vartheta$ : the public supply of goods and services over GDP. We are interested in the effect of the egalitarian bias on public expenditure on the size of government.

Proposition 4 Let preferences satisfy Assumptions 1 and 2. The size of government $\vartheta$-and the net tax revenue $\bar{t}$-is strictly decreasing in $\gamma$.

This is a strong implication of our model of choice of fiscal policy: More egalitarianminded expenditure policies will be at the cost of reducing the size of government to make fiscal policy unanimously acceptable.

\subsection{Majority voting over public spending}

We have already argued that political scientists have underlined that political confrontation takes place more in the domain of public expenditure than in the setting of income taxation. We have characterized the consensus tax function-and the corresponding net tax revenue-as a function of the expenditure policy. We shall now

10 A more extended discussion of this issue in Bandyopadhyay and Esteban (2009). 
complete our analysis by examining the choice over expenditure policies by majority voting.

For the choice over expenditure policies we shall simply transpose the standard analysis of majority voting over linear income taxes. Our problem of choice over the pro-poor bias in expenditure policy is formally similar to the choice over the marginal tax rate $\tau$ studied in this literature. In fact, a linear income tax makes disposable income the convex linear combination of the egalitarian mean income and the individual pretax income with weights $\tau$ and $(1-\tau)$, respectively. Furthermore, when voting for the pro-poor "bias" $\tau$, individuals are assumed to be aware of the effect on labor supply and hence on per-capita income. In our case too, voters will be assumed to take into account that the income tax will be reshuffled following the choice of $\gamma$.

We can now show that a majority voting equilibrium always exists.

Proposition 5 Let $t(\bar{y}) \leq \bar{t}$ and $m<\bar{y}$, with $F(m)=\frac{1}{2}$. Then, a majority voting equilibrium always exists and the chosen expenditure policy, $\gamma^{*}$, is the one preferred by the median voter $\gamma(m)$, that is,

$$
\gamma^{*}=\gamma(m)=\frac{\bar{t}-t(m)}{-\frac{\mathrm{d} \bar{t}}{\mathrm{~d} \gamma}} .
$$

Our result has a flavor of the classic Meltzer and Richard characterization of the majoritarian linear income tax. In their case, the marginal tax rate was proportional to the gap between mean and median incomes, measured at the endogenously determined labor supply. In our case, the chosen egalitarian bias in expenditure policy is proportional to the gap between the taxes paid by the mean and median income earners, also measured at the endogenously determined income tax schedule.

In the next subsection, we derive explicit close-form solutions for the case of CES preferences.

\subsection{CES preferences}

We now restrict individual preferences to be of the CES type. This will permit us to obtain close forms and examine the effects of income inequality, of expenditure bias and of the elasticity of substitution on the tax schedule and on the size of government. In the rest of the paper, we shall empirically test the implications of the model under the CES specification.

The family of CES utility functions is given by:

$$
u(x, g)=\left[x^{\frac{\sigma-1}{\sigma}}+g^{\frac{\sigma-1}{\sigma}}\right]^{\frac{\sigma}{\sigma-1}},
$$

with the elasticity of substitution $\sigma>0$.

The first-order condition for a consensus tax now is

$$
\frac{u_{x}(x, g)}{u_{g}(x, g)}=\left[\frac{y-t(y)}{\gamma \bar{t}+(1-\gamma) t(y)}\right]^{-\frac{1}{\sigma}}=1-\gamma \text {. }
$$


We can thus easily obtain that the consensus income tax is linear

$$
t(y)=\frac{(1-\gamma)^{\sigma} y-\gamma \bar{t}}{(1-\gamma)+(1-\gamma)^{\sigma}} .
$$

Integrating over the incomes $y$, we have that

$$
\bar{t}=\frac{\bar{y}(1-\gamma)^{\sigma}}{1+(1-\gamma)^{\sigma}}=\bar{g} \text { and } \vartheta=\frac{(1-\gamma)^{\sigma}}{1+(1-\gamma)^{\sigma}} .
$$

Therefore, the linear tax schedule will have marginal tax rate $\tau$ and transfer $T$

$$
\tau=\frac{(1-\gamma)^{\sigma}}{(1-\gamma)+(1-\gamma)^{\sigma}} \text { and } T=\frac{\gamma \bar{y}}{\left[1+(1-\gamma)^{1-\sigma}\right]\left[1+(1-\gamma)^{\sigma}\right]} \text {. }
$$

Notice that an increase in the egalitarian bias in public spending $\gamma$ will increase or decrease the marginal tax rate $\tau$ as the elasticity of substitution is smaller or greater than unity, respectively.

Finally, using (11) the majoritarian expenditure policy $\gamma^{*}$ is implicitly defined by

$$
\sigma \gamma^{*} \frac{1+\left(1-\gamma^{*}\right)^{\sigma-1}}{\left[1+\left(1-\gamma^{*}\right)^{\sigma}\right]^{2}}=\frac{\bar{y}-m}{\bar{y}} \equiv M
$$
tion.

We summarize the results obtained for CES preferences in the following Proposi-

Proposition 6 Let individual preferences be CES and let income inequality be measured by the index $M$. Then we have that:

1. the egalitarian bias in public spending $\gamma$ is strictly increasing in inequality;

2. the size of government $\vartheta$ is strictly decreasing in inequality; and

3. the tax schedule is linear and the marginal income tax rate increases or decreases with inequality as the elasticity $\sigma$ is smaller or greater than unity.

\subsection{Discussion}

1. In this model, income is assumed to be exogenous. Why then the poor don't expropriate the rich? This is because the government is committed to partially compensate the individuals with heavy tax contribution. The larger the cash transfers for the poor, the lower the public supply of goods. Since all individuals value the public supply of goods, the poor refrain from expropriation.

2. The degree of substitutability is essential in the relationship between the egalitarian bias and taxation. To see this, in line with the example above, consider the case of publicly supplied goods with no substitutes in the private market. To have an adequate supply of the indispensable publicly supplied goods, the rich have to accept a high level of taxation, even if they will also be financing the 
public supply to the poor. As the expenditure policy becomes more egalitarian, the rich will have to accept higher taxes. However, if the two types of goods are substitutes, the rich will prefer to purchase privately the public ones and the effect of more egalitarian policies will be avoided by reducing taxation.

3. With no assumptions on the tax-transfer function, and with CES preferences, we obtain that the unique $t(\cdot)$ to be consensual is a linear tax function. Consider the effect of an increase by $\Delta$ of an income $y$. Due to the biased expenditure policy, a linear income tax implies that private and public consumption will also increase at the same rate. If preferences had a falling elasticity of substitution of private for public consumption, the income increase would make individuals prefer a more than proportional increase in the supply of the public good and hence would rather favor to increase the marginal tax rate. If the elasticity of substitution were to rise, individuals would have a preference for declining marginal tax rates. Clearly, whether individuals unanimously support a tax function with increasing or decreasing marginal tax rates critically depends upon the change in the elasticity of substitution as the consumption levels rise. A similar argument holds for why the tax rate is shown to be independent of the distribution of income.

4. In our model, the supply of a subset of commodities is the monopoly of the government. This monopoly provides the government with the coercive power to make individuals accept taxation on incomes. How effective this power is critically depends upon the substitutability between this bundle of commodities and the commodities individuals can purchase in the market. Hence, our approach suggests that the rich will lobby more intensely for increasing the substitutability between public and private goods by privatizing as many as possible rather than about the shape of the income tax schedule.

\section{Empirical evidence}

When preferences have constant elasticity of substitution, we have been able to obtain explicit, close-form testable results on the relationship between income inequality and fiscal policy, as recorded in Proposition 6.

We obtain two types of results. One type is the direct effect of inequality on the chosen policy. This can be either on the egalitarian bias of expenditure policy or on the size of government. The second type is the indirect effect of inequality on income taxation, via the consensual re-arrangement associated with the chosen expenditure policy.

In the following, we present evidence supporting the direct and indirect effects of income inequality on fiscal policies. Concerning the direct effects, we have focused on the relationship between inequality and the size of government. We have good data on the size of government for a large sample of countries. In contrast, the specification of the notion of "egalitarian bias" in public expenditure can be controversial, and the data to proxy $\gamma$ limited and of questionable interpretation.

Therefore, based on our results in Proposition 6, we test the following two statements: 
1. There is a positive relationship between the marginal tax rate $\tau$ and income inequality when the elasticity of substitution $\sigma$ is low, and a negative relationship when $\sigma$ is high.

2. The size of government $\vartheta$ is negatively related to inequality. In addition, the marginal effect of inequality on the size of government is larger (in absolute value) if the value of $\sigma$ is lower.

\subsection{Data}

In our main specification, we use an unbalanced panel of 131 countries for the period 1981-2008. This sample contains countries with a high variety of degrees in the democracy score. Our theory does not permit to clearly establish which is the threshold of democracy beyond which the implications of the model cease to be pertinent. Rather than selecting an arbitrary threshold level, we have opted for keeping the full sample (and introducing the level of democracy as a control). For robustness, alternative specifications have also been considered, including dropping non-democracies from the sample, which reduces the number of countries to 115 . A description of the variables employed in the empirical analysis is provided below, while a table containing summary statistics is presented in Table B.1 in "Appendix B."

Dependent variables Our two dependent variables are $\tau$, the marginal income tax rate, and the size of government, $\vartheta$. These variables are measured as follows.

Marginal rate, $\tau$ : It is proxied by the top statutory marginal PIT rate, which is defined as the legally determined marginal tax rate applicable to the top bracket of the personal income tax schedule. This is the only tax schedule information systematically collected for a large sample of countries. The data come from the World Tax Indicators database, International Center for Public Policy at Georgia State University, see Sabirianova et al. (2010) for details.

Size of the Government, $\vartheta$ : It is measured as the ratio of the general government final consumption expenditure as a proportion of total GDP. Data come from the WDI and GDFs databases from the World Bank.

Independent variables The key independent variables in our analysis are income inequality and the elasticity of substitution, $\sigma$.

Income inequality: It is captured in the model by $M$, the median to mean income gap. Data on $M$ are only available for a few country/years. Thus, we have opted to proxy $M$ by the Gini coefficient, $G$, which is the most popular index of inequality. Data for $G$ come from the Standardized World Income Inequality Database (SWIID) (Solt 2009). The SWIID provides comparable Gini indices of market and net income inequality for 153 countries for as many years as possible from 1960 to the present. We use Gini indices of market income inequality which, according to the SWIID definition, are based on pre-tax and pre-government transfers income. ${ }^{11}$

\footnotetext{
11 This dataset combines data from WIDER and other sources to predict missing values in the LIS "mi" (market income) series.
} 
Elasticity of substitution, $\sigma$ : It has been proxied as follows. ${ }^{12}$ The substitutability between the two bundles of commodities depends upon the nature of individual preferences and on the degree of monopoly that the government maintains for some subset of commodities, as discussed earlier. We focus on the latter property since data on public and private expenditure can be more easily accessed. For many OECD countries, the security or the postal systems, for instance, have been a public monopoly until fairly recently. Today, however, it is possible to supplement the public supply of police force or mail services by purchasing additional private security or using courier companies. Our proxy for $\sigma$ is based on the idea that the larger the share of the expenditure channeled through the market, the higher the substitutability between the public and the private provision of these goods. This suggests a simple way to approximate $\sigma$ as the ratio of private versus public spending on some set of commodities for which public provision is usually available. ${ }^{13}$ If all is private, then the elasticity is infinity. If all is public, then the elasticity is zero. A reasonable candidate is health services, since they account for a considerable share of total's government expenditure but this share varies significantly from country to country.

Thus, we proxy $\sigma$ as the ratio of private to public expenditure on health. Data on health expenditures comes from the Global Health Observatory database, World Health Organization and is available for the period 1995-2008 for a large number of countries (193). Our proxy for $\sigma, \sigma^{*}$, is computed as the average of the yearly ratios of private over public health expenditures for each country. Table B.2 in "Appendix B" presents the values of this variable for each of the countries in our dataset.

Indeed, this is a rough proxy for the "true" elasticities of substitution and in the best of cases it contains a sizable measurement error. In the empirical part, we nevertheless try to overcome this limitation by instrumenting $\sigma^{*}$.

Controls Other variables that have been pointed out to have an impact on public spending and taxation decisions are also included in our regressions. These control variables remain the same in all our specifications.

GDPPC: (Log of) income per capita in 2005 PPP dollars, lagged one year (source: Penn World Tables). The rationale for considering this variable is the observation of a

12 There are numerous studies that have dealt with the estimation of the elasticity of substitution between
public and private goods initiated by Barro (1981). However, most of this literature has paid more attention
to the sign of the cross derivative than to the value of the elasticity itself. In addition, these studies typically
focus on a limited number of countries. Thus, we can't make use of these estimates in our empirical analysis.
13 With CES preferences, we have that $\frac{u_{x}(x, g)}{u_{g}(x, g)}=\left[\frac{x}{g}\right]^{-\frac{1}{\sigma}}$. Hence, we can write

$$
\sigma=1-\frac{\ln \frac{u_{x} x}{u_{g} g}}{\ln \frac{u_{x}}{u_{g}}} .
$$

Thus, if the variability of $\frac{u_{x}}{u_{g}}$ across countries is moderate, $\sigma$ is an increasing function of the ratio of private to public value of consumption. Notice that from the firs-order condition (13), we have that $\ln \frac{u_{x}}{u_{g}}=$ $\ln (1-\gamma)<0$. 
positive association between the size of the public sector and income per capita (also known as Wagner's Law), see Easterly and Rebelo (1993).

POP: Log of total population, lagged one year (source: Penn World Tables). Another classical observation is the fact that larger countries tend to spend less on public good provision. Alesina and Wacziarg (1998) provide two explanations for this fact. First, non-rivalrous public goods are shared over larger populations, which results in lower per-capita costs of provision. Second, larger populations tend to exhibit greater heterogeneity in preferences and this often leads to a decrease in public good provision.

POP65: Percentage of population above 65 years, lagged one year (source: the World Bank). A greater fraction of the population over 65 is often associated with large and significant increases in local government expenditure (Shelton 2007).

DEMOC: Democracy indicator, lagged one year (source: Polity IV). ${ }^{14}$ Our theory implicitly assumes that the median income and the decisive voter are the same citizen. However, political rights are restricted to a privileged minority in many countries. We control for the extent of democracy since our sample includes countries with quite heterogeneous political institutions. For robustness, we also consider other ways of dealing with nondemocratic countries, such as excluding them from the sample or allowing for heterogeneous behavior for democratic and nondemocratic countries.

Finally, all our regressions include country fixed effects and year dummies.

\subsection{The marginal tax rate and income inequality}

In this section, we investigate the relationship between the top marginal tax rate, $\tau$, and inequality, which in Sect. 3.4 is established to be conditional upon the value of $\sigma$, the elasticity of substitution between public and private spending.

Our model implies that for low values of $\sigma$, there exists a positive relationship between $\tau$ and inequality that becomes negative for higher values of $\sigma$. A simple way to capture this relation is to consider a linear regression where the marginal tax rate is regressed on inequality and inequality interacted with $\sigma^{*}$, our proxy for $\sigma$, plus some controls. We would expect a positive coefficient for inequality and a negative one for the interacted term, such that for small values of $\sigma^{*}$ the combined effect is positive, but it becomes negative for larger values.

Reverse causality may pose a problem in our empirical analysis. Income inequality may have an effect on the marginal tax rate, as the model postulates. Yet, the amount of redistribution that is possible to implement with the raised taxes might also have a direct effect on inequality. Notice, however, that our measures of inequality are based on market income. This is income before taxes have been collected and before redistribution by the state has taken place. Thus, taxation and social spending have no direct effect on this type of inequality (Milanovic 2000). ${ }^{15}$

\footnotetext{
14 The Democracy indicator ranges from 0 to 10 , where higher values indicate better democratic institutions. Three variables are considered to elaborate this indicator: the competitiveness of political participation, the openness and competitiveness of executive recruitment, and constraints on the chief executive.

15 Just to give an idea of how different inequalities based on market or net income look like, consider the case of Sweden. Sweden is known as being a country with high levels of redistribution and low inequality.
} 
Although a direct link between taxes and market income inequality can be ruled out, an indirect link cannot be discarded. Individual labor supply decisions are likely to be affected by the welfare state and the degree of taxation. High top marginal rates may induce households at the higher end of the income distribution to reduce their labor supply, thus lowering their income. A generous welfare state can have a similar effect at the lower end of the income distribution, since individuals may prefer to work less and receive statecompensation. To address this issue, we lag our measures of inequality and assume that current changes on the tax rate do not have an impact on lagged inequality. Lagging the inequality measures has an additional benefit, since it is natural to expect that changes in the marginal tax rate will occur with some delay with respect to changes in inequality. Three reasons will justify this lag. Firstly, households will need some time to recognize that their relative income position has changed. Secondly, elections do not take place annually, so changes in voter preferences have to wait in most instances until they can effectively be expressed. And thirdly, newly elected governments will also require time to implement policy changes.

Our proxy for the elasticity of substitution between private and public goods, $\sigma^{*}$, might also be endogenous. Countries with low marginal tax rates might be forced to have low public spending and, therefore, a high value of $\sigma^{*}$. This would generate a negative relation between $\sigma^{*}$ and $\tau$, and biased estimators due to reverse causality. We will address this problem by instrumenting $\sigma^{*}$, see below for a discussion.

We estimate the following model for several values of $j$, the inequality lag,

$$
\tau_{i t}=\beta_{1} G_{i t-j}+\beta_{2} G_{i t-j} \sigma_{i}^{*}+\beta_{3} X_{i t-1}+\bar{y}_{i}+\eta_{t}+\epsilon_{i t},
$$

where the subscripts $i=1, \ldots, C$ and $t=1, \ldots, T$ denote country and year, respectively, $\mathrm{G}$ is the Gini coefficient, $\sigma_{i}^{*}$ is our proxy for the elasticity of substitution between private and public goods, $X_{i t-1}$ is a vector of controls (lagged one year), $\bar{y}_{i}$ and $\eta_{t}$ are country and year dummies, respectively, and $\epsilon_{i t}$ is the error term. We have estimated the coefficients using standard fixed effects and instrumental variable techniques. Since all our regressions contain fixed effects, the parameters are identified by the within-country variation of the data. Robust standard errors adjusted for clustering at the country level have been employed in all regressions.

Our main focus is on the effect of inequality lagged five years on the marginal tax rate. This lag is convenient since it ensures that enough time has gone by for elections to take place and new tax policies to be implemented. In addition, this makes our results more comparable with related papers that aggregate the data in 5-year intervals (as Mohl and Pamp 2009, or Shelton 2007). For robustness, we have also considered different lags (4 and 6 years). Table 1 presents our main results. Column 1 considers the relation between the top marginal rate and inequality lagged five years, after imposing $\beta_{2}=0$ in Eq. (18). The coefficient of inequality is negative but not significant. In column 2, the same relation is estimated, this time without imposing

Footnote 15 Continued

Indeed, its average net income Gini over the period considered in this analysis equals 0.23 , which implies that $98 \%$ of the countries of our sample have levels of (net income) inequality that are larger than this value. However, Sweden's average market income Gini is 0.44 , which is above the inequality's median value (55 percentile) and is comparable with that of countries such as Cambodia or Trinidad and Tobago. 


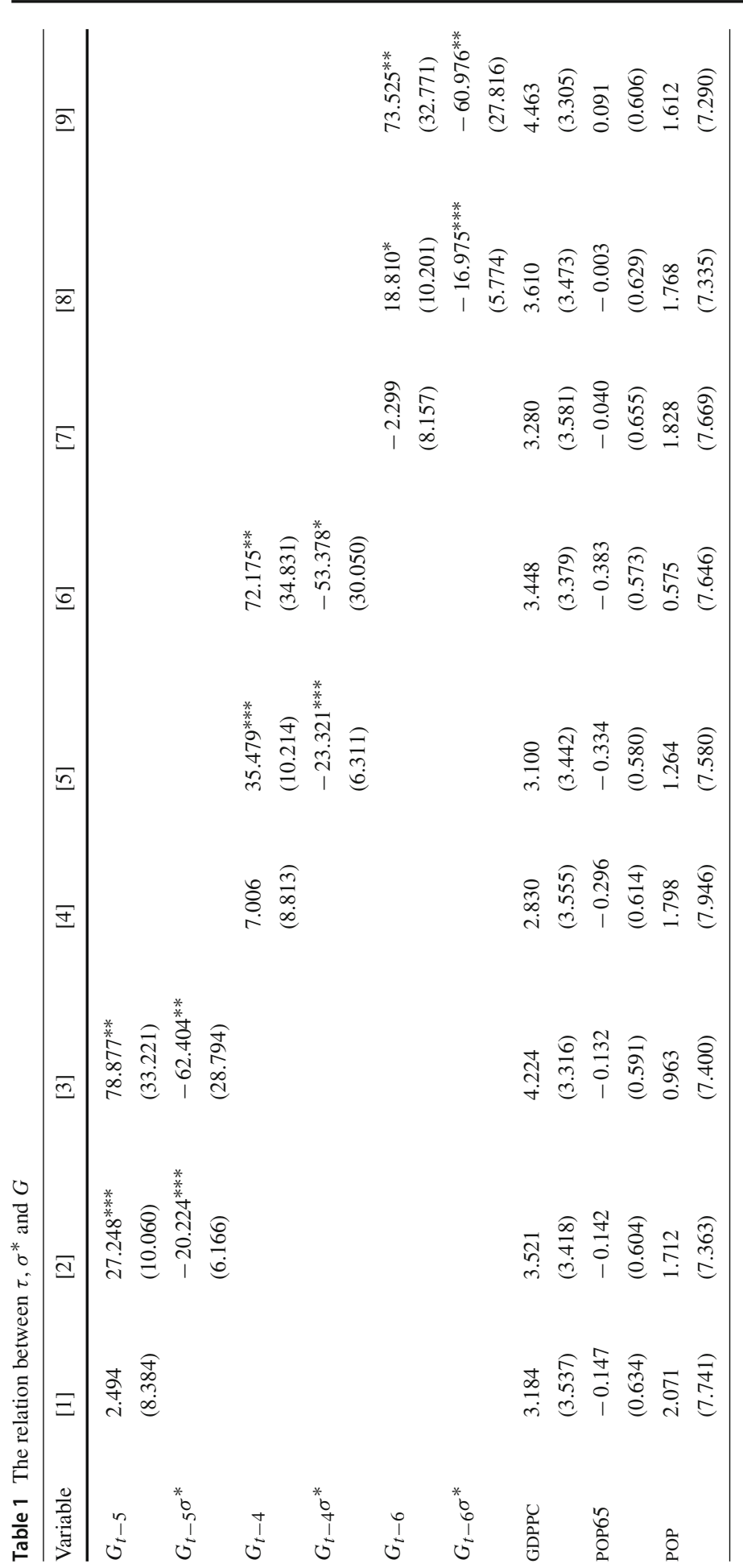




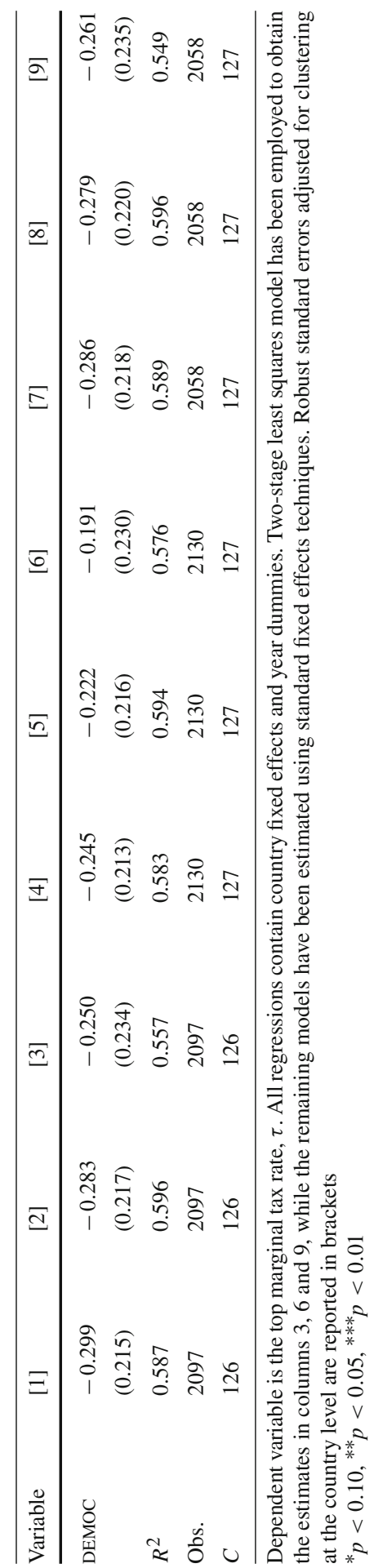


$\beta_{2}=0$. According to the individual $t$ tests, both $\beta_{1}$ and $\beta_{2}$ are significant, the former with a positive sign and the latter with a negative one, just as the theory predicts. ${ }^{16}$ This implies that for moderate values of $\sigma^{*}$ (smaller than 1.34), the relation between the marginal tax rate and inequality is positive. It turns out to be negative, however, for countries with large values of $\sigma^{*}$. The value 1.34 corresponds approximately to the $74 \%$ percentile of the distribution of $\sigma^{*}$. The USA, for instance, has a value of $\sigma^{*}$ equal to 1.25 and, therefore, the model predicts a (small) positive relation between inequality and the top tax rate. ${ }^{17}$

Instrumenting $\sigma^{*}$. As mentioned above, one caveat of the last regression is that the coefficients might be biased due to endogeneity of the elasticity of substitution between private and public goods. In order to find exogenous determinants of $\sigma^{*}$, we have explored the history of the public health system. Its origins date back to the XIX century. At this time, society was experiencing a profound transformation. Industrialization had brought about a rapid urbanization process. Poverty and the lack of basic sanitation in the working class districts of the growing cities provided efficient breeding grounds for communicable diseases. Infants and young adults died in their millions of measles, whooping cough, smallpox, diphtheria, tuberculosis and diarrhea. However, the most devastating epidemics were cholera and typhus that affected people in all age groups. Understanding epidemic diseases in the new society and how to control them required a rethink. Traditional patterns of quarantine and isolation employed in the control of plague proved to be inadequate. In addition, diseases, especially cholera, created violence, rioting and social unrest. At the end of the XIX century, European countries implemented the first state interventions to control epidemics and improve sanitary conditions in mass urban populations, giving rise to the public health system.

Among the many factors that contributed to this development, two seem key. ${ }^{18}$ One, as mentioned above, is the rapid population increase in industrialized cities. The second, is the expansion of trade during the nineteenth century, which was the most important vehicle for the spread of cholera (Porter 1990). The water-borne disease was carried by sailors, traders and shipping workers. Service occupations involving water were always the first groups to succumb.

The importance of trade in a country is connected to the availability of ports. Then, it is reasonable to expect that the ratio of kilometers of coast line over total area, COAST, is positively related to maritime trade. This would imply that this variable is also positively related to the development of the public health system and, therefore, inversely related to $\sigma^{*}$. On the other hand, cities tend to develop and grow more in flat areas that are easily accessible and well communicated. Thus, highly mountainous areas are in principle less suitable for large-scale urbanization. To capture this, we use the proportion of the country that is "mountainous" according to the codings of geographer A. J. Gerard. This variable is denoted as MOUNT. We should expect a negative relation between this variable and the development of large cities. This would imply a negative relation between MOUNT and the development of the public health

\footnotetext{
16 We can also reject the hypothesis that both coefficients are jointly zero, the $p$-value of the corresponding $F$ test being 0.003 .

17 See "Appendix B" for a list of countries and values of $\sigma^{*}$.

18 See Porter (1990) for a detailed analysis on this issue.
} 
system, which in turn, will generate a positive one with $\sigma^{*}$. Finally, it is possible to create a third variable related to $\sigma^{*}$ by combining the information in MOUNT and COAST. A simple way to do this is to consider the ratio of the two, COAST/MOUNT. Given the previous pattern of correlation, we should expect a negative relation between the latter variable and $\sigma^{*} .19$

The simple correlations between $\sigma^{*}$ and the above mentioned variables are $-0.19,0.14$ and -0.15 for the COAST, MOUNT and COAST/MOUNT variables, respectively. Notice that the sign of these correlations are in line with our initial guess.

To obtain potential instruments for $G_{t-j} \sigma^{*}$, we have multiplied the terrain variables by lagged inequality. Provided lagged inequality is predetermined, its interaction with the (exogenous) terrain variables will also be so, implying that the exclusion restriction will hold.

The simple correlations between $G_{t-5} \sigma^{*}$, and $G_{t-5}$ COAST, $G_{t-5}$ COAST/MOUNT, and $G_{t-5}$ MOUNT are $-0.11,-0.11$ and 0.12 , respectively. Table B.3 in "Appendix" presents the first-stage regressions associated with these instruments. When introduced one by one in the first-stage regression, the three variables turn out to be significant (columns 1-3). However, if the three of them are introduced at the same time only $G_{t-5}$ COAST is significant (column 4 in Table B.3). Accordingly, we have reestimated Eq. (18) using $G_{t-5}$ COAST as instrument for $G_{t-5} \sigma^{*}$ and the output is presented in column 3 of Table 1. Although the size of the coefficients differs considerably from those in column 2, the qualitative conclusions are very similar. Countries with values of $\sigma^{*}$ smaller than 1.26 present a positive and significant relation between the top marginal tax rate and inequality and vice versa. ${ }^{20}$ This value of $\sigma^{*}(1.26)$ corresponds to the $72 \%$ percentile of the distribution. This implies that the list of countries with a positive or negative relation between the marginal tax rate and inequality is basically identical as that implied by column 2 .

Columns 4-9 are similar to columns 1-3, but this time inequality lagged 4 (columns 4-6) and 6 years (columns 7-9) has been considered. The corresponding first-stage regressions can be found in columns 5-9 of Table B.3 in "Appendix." The conclusions are identical to those described above: Inequality is never significant when the restriction $\beta_{2}=0$ is imposed. However, a positive and significant coefficient is found for that variable when the interaction of $G$ and $\sigma^{*}$ is also introduced in the regression, whereas the interaction itself has a negative and significant coefficient.

We have also considered other lags of inequality. The results, not reported for the sake of brevity, show that the relation between inequality and the tax rate is weaker for small or for large values of $j$, resulting in estimates of $\beta_{1}$ and $\beta_{2}$ that are not significantly different from zero in most cases. We believe that this pattern of significance is broadly consistent with our theory. Changes in inequality need some time to be realized and expressed so we should not be able to find responses in the short run.

\footnotetext{
19 Obviously, we could also consider the inverse of the previous variable (MOUNT/COUNT) as potential IV and the same is true for MOUNT and COAST. We have actually tried the 6 potential IVs and the ones that turned out to be more correlated with the endogenous variable according to the first-stage regression are three mentioned in the text.

20 Using a $F$ test, the null hypothesis of $\beta_{1}=\beta_{2}=0$ can be rejected at the $10 \%$ level ( $p$ value 0.0519$)$. On the other hand, tests of the hypothesis $\beta_{2}=0$ robust to weak instruments - such as the Anderson-Rubin test-still reject the null at conventional significance levels ( $p$ value 0.024).
} 
Table 2 The relation between $\tau, \sigma^{*}$ and $G$ in democracies

\begin{tabular}{|c|c|c|c|c|c|}
\hline Variable & [1] & [2] & [3] & [4] & [5] \\
\hline$G_{t-5}$ & $\begin{array}{l}5.902 \\
(8.363)\end{array}$ & $\begin{array}{l}27.140^{* * *} \\
(9.830)\end{array}$ & $\begin{array}{l}4.475 \\
(8.593)\end{array}$ & $\begin{array}{l}25.356^{* *} \\
(9.902)\end{array}$ & $\begin{array}{l}91.281^{* *} \\
(43.907)\end{array}$ \\
\hline$G_{t-5} \times \mathrm{ND}$ & $\begin{array}{l}-0.293 \\
(0.202)\end{array}$ & $\begin{array}{l}0.118 \\
(0.668)\end{array}$ & & & \\
\hline$G_{t-5} \sigma^{*}$ & & $\begin{array}{l}-18.647^{* * *} \\
(6.544)\end{array}$ & & $\begin{array}{l}-18.308^{* * *} \\
(6.193)\end{array}$ & $\begin{array}{l}-76.112^{*} \\
(40.116)\end{array}$ \\
\hline$G_{t-5} \sigma^{*} \times \mathrm{ND}$ & & $\begin{array}{l}-14.746 \\
(28.438)\end{array}$ & & & \\
\hline GDPPC & $\begin{array}{l}3.453 \\
(3.654)\end{array}$ & $\begin{array}{l}3.629 \\
(3.410)\end{array}$ & $\begin{array}{l}0.559 \\
(3.620)\end{array}$ & $\begin{array}{l}0.779 \\
(3.419)\end{array}$ & $\begin{array}{l}1.474 \\
(3.352)\end{array}$ \\
\hline POP65 & $\begin{array}{l}-0.186 \\
(0.622)\end{array}$ & $\begin{array}{l}-0.142 \\
(0.599)\end{array}$ & $\begin{array}{l}-0.249 \\
(0.614)\end{array}$ & $\begin{array}{l}-0.256 \\
(0.585)\end{array}$ & $\begin{array}{l}-0.278 \\
(0.589)\end{array}$ \\
\hline POP & $\begin{array}{l}2.353 \\
(7.661)\end{array}$ & $\begin{array}{l}1.960 \\
(7.335)\end{array}$ & $\begin{array}{l}0.699 \\
(8.415)\end{array}$ & $\begin{array}{l}0.001 \\
(8.077)\end{array}$ & $\begin{array}{l}-2.203 \\
(8.391)\end{array}$ \\
\hline DEMOC & $\begin{array}{l}-0.296 \\
(0.216)\end{array}$ & $\begin{array}{l}-0.278 \\
(0.216)\end{array}$ & $\begin{array}{l}-0.289 \\
(0.213)\end{array}$ & $\begin{array}{l}-0.280 \\
(0.215)\end{array}$ & $\begin{array}{l}-0.250 \\
(0.243)\end{array}$ \\
\hline$R^{2}$ & 0.589 & 0.596 & 0.615 & 0.622 & 0.547 \\
\hline Obs. & 2097 & 2097 & 1889 & 1889 & 1889 \\
\hline C & 126 & 126 & 112 & 112 & 112 \\
\hline
\end{tabular}

Dependent variable is the top marginal tax rate. All regressions contain country fixed effects and year dummies. ND is a dummy for nondemocratic countries. Columns 1 and 2 allow for heterogeneous behavior for democratic and nondemocratic countries. Columns 3-5 present results for democratic countries exclusively. Column 5 has been estimated using 2SLS, while the remaining columns use standard fixed effects techniques, see the text for details. Robust standard errors adjusted for clustering are reported in brackets ${ }^{*} p<0.10,{ }^{* *} p<0.05,{ }^{* * *} p<0.01$

Similarly, changes in inequality that happened a long time ago might not be relevant any more since more recent events might be motivating different responses.

The results above have been obtained considering all countries for which data are available, since our theory does not permit to clearly establish which is the threshold of democracy beyond which the implications of the model do not apply. For the sake of robustness, Table 2 presents alternative specifications. We first consider the possibility that the effect of inequality on the marginal tax rate differs in democracies and non-democracies. To capture this, we have introduced in the regressions the interaction of the inequality variables (lagged 5 years) and a dummy for nondemocracies (ND). Following Persson and Tabellini (2006), a country is considered non-democratic $(\mathrm{ND}=1)$ if the polity 2 variable in the Polity IV dataset is negative throughout the period. ${ }^{21}$ Columns 1 and 2 in Table 2 present the results that are qualitatively identical to those presented in columns 1 and 2 of Table 1: Lagged inequality is not related to the marginal tax rate (column 1), but it appears to be so when the interaction of $G$ and $\sigma^{*}$ is introduced in the regression (column 2). The variables that

21 The polity 2 variable ranges from - 10 (full autocracy) to 10 (full democracy). 
capture the heterogeneous effects for non-democracies $\left(G_{t-5} \times \mathrm{ND}\right.$ and $\left.G_{t-5} \sigma^{*} \times \mathrm{ND}\right)$ are not significant, suggesting the absence of such effects. ${ }^{22}$ Columns 3 to 5 in Table 2 reproduce columns 2-4 in Table 1, this time excluding non-democracies from the sample. Again, the results are very similar to those in our main specification.

\subsection{The relation between the size of government and inequality}

In this section, we investigate the relationship between the size of the state, $\vartheta$, and inequality. It follows from expression (15) that $\vartheta$ is a decreasing function of $\gamma$. In addition, since $\gamma$ can be approximated by $M / \sigma$ in most empirically relevant cases it follows that $\vartheta$ is also a decreasing function of $M / \sigma$. Although according to the model presented in the previous sections this relation is not linear, it seems reasonable to consider as a starting point whether a linear approximation can capture the implications of the theory.

We use a similar framework to the one considered in the previous section. In this case, we estimate

$$
\vartheta_{i t}=\beta_{1} G_{i t-j}+\beta_{2} \frac{G_{i t-j}}{\sigma_{i}^{*}}+\beta_{3} X_{i t-1}+\bar{y}_{i}+\eta_{t}+\epsilon_{i t} .
$$

In accordance with the theory, we should expect a value of $\beta_{1}$ not significantly different from zero together with a negative and significant value for $\beta_{2}$, which would imply that the marginal effect of inequality on the size of state is decreasing in $\sigma$ in absolute value.

As in the previous section, we consider lagged values of inequality. One could expect that the size of state would respond even slower than the tax rate to changes in inequality, since implementing visible reductions or increases in this variable can take several years. For this reason, we analyze the impact on the current size of the state of changes in inequality occurring with a lag of 5, 6 and 7 years.

Table 3 reports our estimates of Eq. (19). Columns 1, 4, and 7 present the results obtained after imposing the restriction $\beta_{2}=0$, for different lags of inequality (57 years). The sign of the coefficients of $G_{t-j}$ is always negative, but estimates are never significant. If the restriction $\beta_{2}=0$ is dropped (see columns 2,5 , and 8 ), the coefficients of $G_{t-j}$ are still not significant but those associated with $G_{t-5} / \sigma^{*}$ are positive and significant, as the theory predicts. ${ }^{23}$

Since there are good reasons to suspect that $\sigma^{*}$ can be endogenous, we have constructed instruments for $G_{t-j} / \sigma^{*}$ in a similar fashion as before. This time, we have divided (lagged) inequality by the terrain variables introduced in the previous section. The first-stage regressions (see Table B.4 in "Appendix") show that only $G_{t-j}$ COAST/MOUNT is significant this time. Columns 3, 6 and 9 in Table 3 present estimates of (19) with $G_{t-j} / \sigma^{*}$ instrumented by $G_{t-j}$ COAST/MOUNT. As before, the inequality variable on its own is not significant. However, (lagged) inequality divided

\footnotetext{
22 This finding is consistent with recent evidence that shows that the relation between democracy and inequality is tenuous, see Acemoglu et al. (2013).

23 In all cases, the joint hypothesis of $\beta_{1}=\beta_{2}=0$ can be rejected at the $5 \%$ significance level.
} 


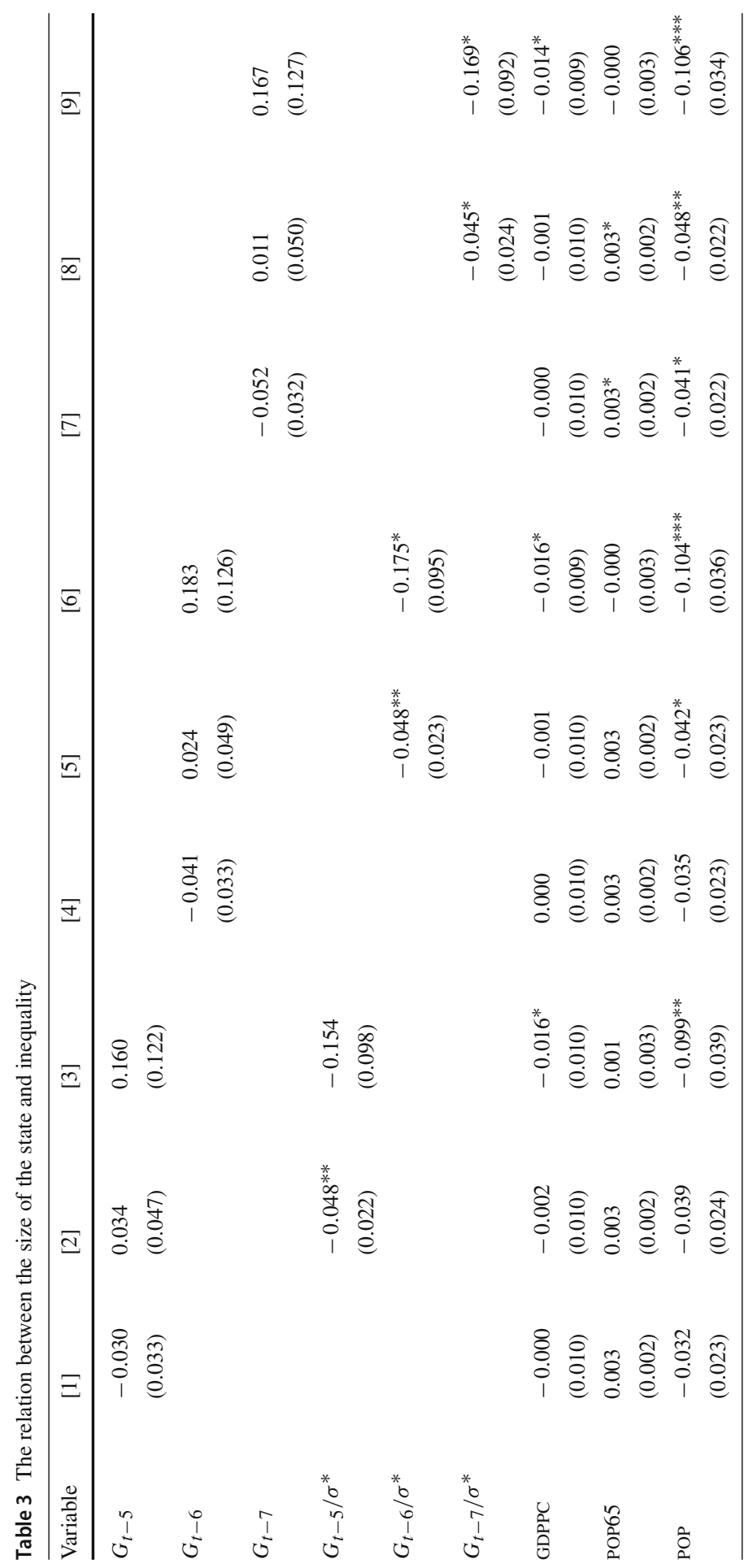




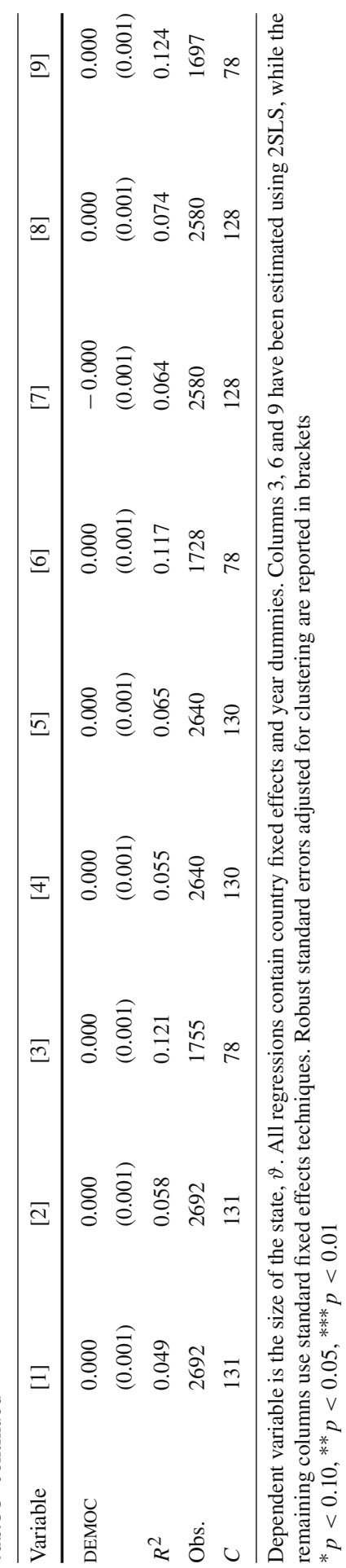


Table 4 Size of the state and inequality in democracies

\begin{tabular}{llllll}
\hline Variable & {$[1]$} & {$[2]$} & {$[3]$} & {$[4]$} & {$[5]$} \\
\hline$G_{t-5}$ & -0.027 & 0.045 & -0.026 & 0.050 & 0.216 \\
& $(0.037)$ & $(0.053)$ & $(0.039)$ & $(0.056)$ & $(0.170)$ \\
$G_{t-5} \times \mathrm{ND}$ & -0.000 & -0.001 & & & \\
& $(0.001)$ & $(0.001)$ & & & \\
$G_{t-5} / \sigma^{*}$ & & $-0.050^{* *}$ & & $-0.053^{* *}$ & -0.179 \\
& & $(0.023)$ & & $(0.023)$ & $(0.115)$ \\
$G_{t-5} \sigma^{*} \times \mathrm{ND}$ & & -0.006 & & & \\
& & $(0.079)$ & & & \\
GDPPC & -0.000 & -0.001 & -0.004 & -0.005 & -0.016 \\
& $(0.010)$ & $(0.010)$ & $(0.012)$ & $(0.012)$ & $(0.012)$ \\
POP65 & 0.003 & 0.003 & 0.003 & 0.002 & 0.001 \\
& $(0.002)$ & $(0.002)$ & $(0.002)$ & $(0.002)$ & $(0.003)$ \\
POP & -0.032 & -0.038 & -0.029 & -0.036 & $-0.089^{* *}$ \\
& $(0.023)$ & $(0.024)$ & $(0.026)$ & $(0.027)$ & $(0.042)$ \\
DEMOC & 0.000 & 0.000 & 0.000 & 0.000 & 0.000 \\
& $(0.001)$ & $(0.001)$ & $(0.001)$ & $(0.001)$ & $(0.001)$ \\
$R^{2}$ & 0.049 & 0.059 & 0.043 & 0.055 & 0.101 \\
Obs. & 2692 & 2692 & 2402 & 2402 & 1555 \\
$C$ & 131 & 131 & 115 & 115 & 115 \\
\hline Depen & & & &
\end{tabular}

Dependent variable is the size of the state $\vartheta$. All regressions contain country fixed effects and year dummies. ND is a dummy for nondemocratic countries. Columns 1 and 2 allow for heterogeneous behavior for democratic and nondemocratic countries. Columns 3-5 present results for democratic countries exclusively. Column 5 has been estimated using 2 SLS while the remaining columns use standard fixed effects techniques, see the text for details. Robust standard errors adjusted for clustering are reported in brackets

${ }^{*} p<.10,{ }^{* *} p<.05,{ }^{* * *} p<.01$

by $\sigma$ has a negative coefficient that is still significant at the $10 \%$ level (with the exception of the coefficient of $G_{t-5} / \sigma^{*}$ - column 3-, for which the $p$ value is 0.11$) .{ }^{24}$

We have also considered larger values $j$ (namely, $j=\{8,9,10\}$ ), and in these cases, the significance of the interacted term tends to vanish, suggesting that changes that happen too far back in time have no effect on the current size of the state.

To account for the fact that the degree of democracy varies greatly among the countries in our sample, alternative specifications have also been estimated and the results are reported in Table 4. As in the previous section, we have allowed for the possibility of heterogeneous effects for democratic and non-democratic countries (columns 1 and 2) and we have reestimated columns 1-3 in Table 3 dropping non-democracies (columns 3-5 in Table 4). Neither of these variations had any effect on the conclusions obtained from our main specification.

\footnotetext{
24 Similar results are obtained if techniques robust to weak instruments, as the Anderson-Rubin test, are employed to for the significance of $\beta_{2}$.
} 


\section{Concluding remarks}

In this paper, we have provided an integrated analysis of income taxation and public expenditure. Individuals care about the reduction of their disposable income because of taxation, but also care about the benefits they will receive from the goods and services supplied by the government. How beneficial public expenditure is to each particular tax payer depends on the specific egalitarian bias of the expenditure policy, as this fixes the return to the tax paid. We study the case where the political debate is on the distributional bias of the expenditure policy and, once the bias has been chosen by majority voting, taxes and size of government are adjusted to achieve consensus (and welfare efficiency on the way).

The first prediction of our voting model is straightforward. Higher inequality will make the median voter vote for more egalitarian expenditure policies. This result, however, has two more subtle implications, once we take into account the readjustment of the other fiscal policies. One is that the relationship between taxation and inequality is non-monotonic because its sign depends on the degree of substitutability between the publicly and the market supplied goods. The second one is that the relationship between inequality and the chosen size of government is again mediated by the degree of substitutability: Substitutability reduces the marginal effect of inequality on the size of government. We empirically test the two implications. The first result is remarkable because the literature has so far been unable to identify a solid and significant relationship between inequality and taxation. The second issue has not yet been so extensively studied in the literature. The few existing empirical studies have tested a possible simple relationship between inequality and size of government. Our model tells us that this has to be conditioned by the substitutability. Indeed, we find that while in isolation inequality does not have a significant role, we obtain a significant relationship once inequality is adequately interacted with substitutability.

These two results underline the critical importance of the substitutability between the publicly and market supplied goods. In this paper, we have taken just a first step and have considered such a fundamental policy as exogenously given. In our view, the literature has not given to this issue the relevance it deserves. In the political as well as in the academic debate, the issue of privatizing public services has been seen as an issue about improving the efficiency in the management of a service. However, it is obvious that the more the services are privatized, the less indispensable is the state and hence the higher the resistance to taxation. Developing a full politico-economic model of privatizations is in our research agenda.

Acknowledgements Mayoral and Esteban research has been funded by the Spanish Ministry of Economy and Competitiveness Grant, through the Severo Ochoa Programme for Centres of Excellence in R\&D (SEV2015-0563) and Grant ECO 2015-66883-P, Generalitat de Catalunya Project 2017SGR1359 $\Delta$, and the National Science Foundation Grant SES-1629370. Useful comments by Jordi Caballé, Eliana la Ferrara and Kalle Moene are gratefully acknowledged. Andrew Gianou has provided us with excellent research assistance.

\section{Compliance with ethical standards}

Conflict of interest The authors declare that they have no conflict of interest. 
Ethical approval This article does not contain any studies with human or animals participants performed by any of the authors.

Informed consent This article does not contain any information that requires informed consent.

Open Access This article is distributed under the terms of the Creative Commons Attribution 4.0 International License (http://creativecommons.org/licenses/by/4.0/), which permits unrestricted use, distribution, and reproduction in any medium, provided you give appropriate credit to the original author(s) and the source, provide a link to the Creative Commons license, and indicate if changes were made.

\section{Appendix A: Proofs}

\section{Proposition 3}

Proof Totally differentiating (8) with respect to $t(\cdot)$ and $y$ and rearranging, we obtain

$$
\frac{\mathrm{d} t(\cdot)}{\mathrm{d} y}=\frac{u_{x g} u_{x}-u_{x x} u_{g}}{\left(u_{x g} u_{x}-u_{x x} u_{g}\right)+\gamma\left(u_{x g} u_{g}-u_{g g} u_{x}\right)} .
$$

Observe that the numerator and the first term in the denominator are identical and they are positive because of Assumption 1. Because of Assumption 1, again, the second term in the denominator is also positive. Therefore, the marginal tax rate is positive and less than unity.

\section{Proposition 4}

Proof We simply have to show that $\bar{t}$ is strictly decreasing in $\gamma$.

Totally differentiating (2) with respect to $t(y)$ and $\bar{t}$, we obtain

$$
\frac{\mathrm{d} \bar{t}}{\mathrm{~d} \gamma}=\frac{\int \frac{\partial t(y)}{\partial \gamma} \mathrm{d} F(y)}{1-\int \frac{\partial t(y)}{\partial \bar{t}} \mathrm{~d} F(y)}
$$

It can be easily shown that the integral in the denominator is strictly negative. Hence, the full denominator is positive. It follows that $\frac{\mathrm{d} \bar{t}}{\mathrm{~d} \gamma}$ has the same sign as the numerator.

Differentiating the first-order condition with respect to $t(y)$ and $\gamma$, we obtain

$$
\frac{\partial t(y)}{\partial \gamma}=-\frac{u_{g}+[\bar{t}-t(y)]\left[u_{x g}-(1-\gamma) u_{g g}\right]}{-u_{x x}+2(1-\gamma) u_{x g}-(1-\gamma)^{2} u_{g g}} .
$$

Taking into account that

$$
\frac{\partial u_{g}}{\partial t(y)}=-u_{x g}+(1-\gamma) u_{g g}
$$

We can write

$$
\frac{\partial t(y)}{\partial \gamma}=-u_{g} \frac{1-\frac{\bar{t}-t(y)}{t(y)} \frac{t(y)}{u_{g}} \frac{\partial u_{g}}{\partial t(y)}}{-u_{x x}+2(1-\gamma) u_{x g}-(1-\gamma)^{2} u_{g g}} .
$$


By Assumption 1, the denominator is positive and by Assumption 2 the numerator is positive as well. Hence, $\frac{\partial t(y)}{\partial \gamma}<0$ and also $\frac{\mathrm{d} \bar{t}}{\mathrm{~d} \gamma}<0$.

\section{Proposition 5}

Proof We obtain the characterization of the chosen policy by differentiating the individual utility with respect to $\gamma$ to get

$$
\frac{\mathrm{d} u(x(y), g(y))}{\mathrm{d} \gamma}=u_{x} \frac{\mathrm{d} x(y)}{\mathrm{d} \gamma}+u_{g} \frac{\mathrm{d} g(y)}{\mathrm{d} \gamma} .
$$

Since the tax is consensual, we can use (8) to obtain

$$
\frac{\mathrm{d} u(x(y), g(y))}{\mathrm{d} \gamma}=u_{g}\left[\frac{\mathrm{d} g(y)}{\mathrm{d} \gamma}+(1-\gamma) \frac{\mathrm{d} x(y)}{\mathrm{d} \gamma}\right] .
$$

We know that

$$
\frac{\mathrm{d} x(y)}{\mathrm{d} \gamma}=-\frac{\mathrm{d} t(y)}{\mathrm{d} \gamma}
$$

and that

$$
\frac{\mathrm{d} g(y)}{\mathrm{d} \gamma}=(\bar{t}-t(y))+\gamma \frac{\mathrm{d} \bar{t}}{\mathrm{~d} \gamma}+(1-\gamma) \frac{\mathrm{d} t(y)}{\mathrm{d} \gamma} .
$$

Hence,

$$
\frac{\mathrm{d} u(x(y), g(y))}{\mathrm{d} \gamma}=u_{g} \frac{\mathrm{d} \bar{t}}{\mathrm{~d} \gamma}\left[\gamma-\frac{\bar{t}-t(y)}{-\frac{\mathrm{d} \bar{t}}{\mathrm{~d} \gamma}}\right] .
$$

Bearing in mind that $\frac{\mathrm{d} \bar{t}}{\mathrm{~d} \gamma}<0$ is independent of $y$, if we denote by $\hat{y}$ the solution to $t(\hat{y})=\bar{t}$, we have that $\frac{\mathrm{d} u(x(y), g(y))}{\mathrm{d} \gamma}<0$ for all $y>\hat{y}$. Consequently, all individuals with $y \geq \hat{y}$ will prefer $\gamma(y)=0$. Further, all individuals with $y<\hat{y}$-this includes the median income-will prefer $\gamma(y)>0$, which is decreasing in $y$. Hence, the $\gamma$ with majoritarian support is the one preferred by the voter with the median income.

\section{References}

Acemoglu D, Naidu S, Restrepo P, Robinson J (2013) Democracy, redistribution and inequality. NBER working papers 19746

Alesina A, Wacziarg R (1998) Openness, country size and government. J Public Econ 69:305-321

Arrow KJ (1971) A utilitarian approach to the concept of equality in public expenditures. Q J Econ 85:409_ 15

Bandyopadhyay S, Esteban J (2009) Redistributive taxation and public expenditures. Barcelona GSE, wp 416

Barro R (1981) Output effects of government purchases. J Polit Econ 89:1086-1121

Borck R (2007) Voting, inequality, and redistribution. J Econ Surv 21:90-109 
Bouakez H, Rebei N (2007) Why does private consumption rise after a government spending shock? Can J Econ Revue Canadienne d'Economie 40:954-979

Bruninger T (2005) A partisan model of government expenditure. Public Choice 125:409-429

Budge I, Klingemann D, Volkens A, Bara J, McDonald M (2001) Mapping policy preferences. Estimates for parties, electorates, governments 1945-1999. Oxford University Press, Oxford

Budge I, Klingemann D, Volkens A, Bara J, McDonald M (2006) Mapping policy preferences (II). Estimates for parties, electorates, governments 1995-2003. Oxford University Press, Oxford

Easterly W, Rebelo S (1993) Fiscal policy and economic growth: an empirical investigation. J Monet Econ 32:417-458

Meltzer AH, Richard SF (1981) A rational theory of the size of government. J Polit Econ 89:914-927

Milanovic B (2000) The median-voter hypothesis, income inequality, and income redistribution: an empirical test with the required data. Eur J Polit Econ 16:367-410

Mohl P, Pamp O (2009) Income inequality and redistributional spending: an empirical investigation of competing theories. Public Finance Manag 9(2):179-234

Office of National Statistics (2013) Effects of taxes and benefits on UK household income. https://www.ons. gov.uk/peoplepopulationandcommunity/personalandhouseholdfinances/incomeandwealth/bulletins/ theeffectsoftaxesandbenefitsonhouseholdincome/2013-07-10

Persson T, Tabellini G (2006) Democracy and development: the devil in the details. Am Econ Rev 96:319324

Porter M (1990) Competitive advantages of nations. Free Press, New York

Roberts KWS (1977) Voting over income tax schedules. J Public Econ 8:329-340

Romer T (1975) Individual welfare, majority voting and the properties of the linear income tax. J Public Econ 4:163-185

Sabirianova P, Buttrick P, Duncan D (2010) Global reform of personal income taxation, 1981-2005: evidence from 189 countries. Nat Tax J 63(3):447-478

Scervini F (2012) Empirics of the median voter: democracy, redistribution and the role of the middle class. $\mathrm{J}$ Econ Inequal 10:529-550

Shelton C (2007) The size and composition of government expenditure. J Public Econ 91:2230-2260

Solt F (2009) Standardizing the world income inequality database. Soc Sci Q 90:231-242

Tsebelis G, Chang ECC (2004) Veto players and the structure of budgets in advanced industrialized countries. Eur J Polit Res 43:449-476

Publisher's Note Springer Nature remains neutral with regard to jurisdictional claims in published maps and institutional affiliations. 